\title{
PENILE SELF-AMPUTATION IN A PATIENT WITH SCHIZOPHRENIA, WHILE ON CLOZAPINE AUGMENTATION WITH MODAFINIL: A CASE REPORT
}

\author{
NRK Anish ${ }^{*}$, Vidhukumar Karunakaran ${ }^{2}$, Anil Prabhakaran $^{3}$ \\ ${ }^{1}$ Psychiatrist, Government Mental Health Centre, Trivandrum. \\ ${ }^{2}$ Head, Dept. of Psychiatry, Medical College, Ernakulam. \\ ${ }^{3}$ Head, Dept. of Psychiatry, Medical College, Thiruvananthapuram. \\ *Correspondence: Government Mental Health Centre, Trivandrum. Pin: 695005 E-mail: anish.nrk@gmail.com
}

\begin{abstract}
Genital self-mutilation is extremely rare and is seen in psychotic illnesses with associated risk factors like commanding hallucinations, religious delusions, past suicide attempts, depression, personality disorder, substance abuse or gender identity problems. We report a case of total penile self-amputation in a 23-yearold male without any of these risk factors. He was diagnosed with schizophrenia and was well maintained on clozapine $150 \mathrm{mg}$ with (an SOS) prescription of modafinil $100 \mathrm{mg}$ in the morning. Modafinil has not been associated with self mutilatory behaviour in human clinical trials so far.
\end{abstract}

Keywords: penile self amputation, self-mutilation in schizophrenia, modafinil

\section{INTRODUCTION}

Genital self-mutilation is a rare phenomenon, with a little over 100 cases reported in the literature, and total penile self-amputation is even rarer. ${ }^{1}$ It is commonly associated with psychotic illnesses, and the risk factors have been suggested to be commanding hallucinations, religious delusions, sexual conflict associated with guilt, past suicide attempts, features of depression, severe childhood deprivation, and personality disorders. ${ }^{2,3}$ Other risk factors postulated are substance abuse, social isolation and gender identity problems. ${ }^{1,4}$ We report a case of genital self-amputation in a young male without any of these risk factors, and who was apparently well adjusted at his workplace and home.

\section{CASE REPORT}

AK, a 23-year-old unmarried male working as a typist, presented to the casualty, accompanied by his mother, with history of severing his penis with a razor blade. The patient had flushed the cut off portion in the closet. Hence, re-implantation surgery was not possible. Instead, a meatoplasty was done. The patient was transferred to the psychiatry department after six days.

AK was on treatment for schizophrenia, which had started four years back. He was maintained for the last three years with a single night time dose of clozapine $150 \mathrm{mg}$. Clozapine levels were not monitored. He joined his job as a typist one and a half year back and was regular at the workplace. He had occasional daytime sleepiness. One year back, he was advised by the treating psychiatrist to take

Please cite this article as Anish NRK, Karunakaran V, Prabhakaran A. Penile self-amputation in a patient with schizophrenia, while on clozapine augmentation with modafinil: a case report. Kerala Journal of Psychiatry 2017; 30(2): 88-9. DOI: 10.30834/KJP.30.2.2018.125 
modafinil $100 \mathrm{mg}$ during working days if feeling sleepy, as an SOS medication in the morning. When found drowsy in the office hours, his colleagues used to make fun of him for getting paid for doing nothing. Subsequently, the patient developed a delusion that in order to get better pays and prospects, one should be ready to suffer pain. He began to experiment with inflicting injuries in different parts of the body (that went unnoticed) for past six months, which ended up in the penile selfamputation. Interestingly, the patient reportedly did not perceive any pain during the act of amputation. In fact, the patient found the suturing of the wound in the emergency services more painful compared to the self-amputation.

There was no associated hallucinatory behaviour, obsessive symptoms, dissociative symptoms, substance abuse or problems with gender identity. There was no family history of mental illness. The patient reported a decrease in his masturbatory practices of a few months duration and denied having any ejaculatory dysfunction, erectile dysfunction or sexual relationships. There was a history of childhood physical abuse by the father whom he lost when he was 13 years of age. Premorbidly, he was well adjusted except for having only a few friends. On examination, the patient was lodging the single delusion. The affect was inappropriate with poor insight.

\section{DISCUSSION}

Penile self-amputation in psychotic illnesses is a rare phenomenon, and no studies have been reported so far from this part of the country. Its existence has been associated with commanding hallucinations in van Gogh syndrome and religious delusions in Klingsor syndrome. ${ }^{5,6}$ Other risk factors discussed are comorbid substance abuse and lack of social support. ${ }^{7}$ The patient in our report did not have any of these risk factors. His drug compliance was satisfactory and he had good social support.

The patient was also on SOS modafinil. Though, in clinical trials in humans, modafinil is known to cause excitation, insomnia, anxiety, irritability, aggressiveness, confusion, nervousness, tremor, palpitations and sleep disturbances, there is no evidence for it causing self mutilatory behaviour. However, other psychostimulants like amphetamine are associated with self mutilatory behaviour, especially genital self-mutilation. ${ }^{8,9}$ The absence of significant pain during the act of amputation has been described in previous case reports, ${ }^{10}$ and the patient in our case also did not perceive any pain. The patient was lost from follow-up after one month of review. It is interesting to note that the patient's self-injurious behaviour started following a delusion that arose in the backdrop of critical comments at the workplace. This case also shows the need for specifically enquiring for the presence of such possible delusions in otherwise well-maintained patients with schizophrenia.

\section{REFERENCES}

1. Helen S, Richard EP, Michael F jnr, David MQ. Genital self mutilation. Int J Urol 2006; 13: 1358-60.

2. Schweitzer I. Genital self amputation and the Klingsor syndrome. Aust N Z J Psychiatry 1990; 24(4): 566-9.

3. Hall DC, Lawson BZ, Wilson LG. Command hallucination and self amputation of penis and hand during a first psychotic break. J Clin Psychiatry 1981; 42(8):322-4.

4. Rana A, Johnson D. Sequential self-castration and amputation of the penis. Br J Urol 1993; 71:750.

5. Vafaei B. Two case reports of self mutilation or van gogh syndrome. Acta Med Iran 2003; 41:199-201.

6. Ames D. Autocastration and biblical delusions in schizophrenia. Br J Psychiatry 1987; 150:347.

7. Aboseif S, Gomez R, McAninch JW. Genital self mutilation. J Urol 1993; 150:1143-6.

8. Kratofil PH, Baberg HT, Dimsdale JE. Self-mutilation and severe self-injurious behavior associated with amphetamine psychosis. Gen Hosp Psychiatry 1996; 18(2):117-20.

9. Israel JA, Lee K. Amphetamine usage and genital self mutilation. Addiction 2002; 97(9):1215-8.

10. Thomas NW, Ram CK. Amputee fetishism and genital mutilation: Case report and literature review. J Sex Marital Ther 2000; 26: 339-44.

\footnotetext{
Source of support: None

Conflict of interest: None declared
}

First submitted: $26^{\text {th }}$ December 2017

Published online: $4^{\text {th }}$ March 2018 